\title{
The Effect of Statewide Residency Restrictions on Sex Offender Post-Release Housing Mobility
}

\author{
Jason Rydberg \\ Doctoral Student \\ Michigan State University \\ 560 Baker Hall \\ East Lansing, MI 48824 \\ $\mathrm{Ph}:$ 517.432.2274 \\ Email: rydbergj@msu.edu
}

Eric Grommon

Assistant Professor

School of Public and Environmental Affairs

Indiana University-Purdue University, Indianapolis

801 W. Michigan St.

Indianapolis, IN 46202

$\mathrm{Ph}: 317.278 .9481$

Email: egrommon@iupui.edu

Beth M. Huebner

Associate Professor

University of Missouri - St. Louis

One University Boulevard

324 Lucas Hall

St. Louis, MO 63121

$\mathrm{Ph}: 314.516 .5043$

Email: huebnerb@umsl.edu

Timothy Bynum

Professor

Michigan State University

560 Baker Hall

East Lansing, MI 48824

$\mathrm{Ph}:$ 517.355.2196

Email: bynum@msu.edu

This project was supported by funding from the National Institute of Justice, Office of Justice Programs, U.S. Department of Justice (2008-DD-BX-0002). An earlier version of this paper was presented in 2010 at the American Society of Criminology annual meeting in San Francisco. We would like to thank William S. Davidson II for his helpful comments. The opinions, conclusions, and recommendations reflect those of the authors and not any aforementioned agency.

This is an Accepted Manuscript of an article published online in Justice Quarterly on March 7, 2012, available from: http://www.tandfonline.com/10.1080/07418825.2012.667141.

Final version published as: Rydberg, J., Grommon, E., Huebner, B. M., \& Bynum, T. (2014). The effect of statewide residency restrictions on sex offender post-release housing mobility. Justice Quarterly, 31(2), 421-444. 


\begin{abstract}
Securing stable housing may be difficult for returning offenders in general and these concerns may be exacerbated for sex offenders. In addition to the barriers faced by other returning offenders, sex offenders face intense stigma and once released to the community, are also subject to additional legal restrictions. The current study explores the effect of statewide residency restriction policies on housing mobility using a unique sample of male sex offenders released in a Midwestern state. The research is based on a quasi-experimental cohort control group design and describes the frequency and correlates of movement for pre and post-statewide residency restriction legislation samples. Sex offenders released after the implementation of residency restrictions moved more often and had relatively high degrees of housing mobility compared to offenders released prior to the legislation. The results have important implications for reentry programming and post-release services for sex offenders.
\end{abstract}

KEYWORDS: Sex offenders, sex offender legislation and policy, residency restrictions, prisoner reentry, housing movement

\title{
Citation
}

Rydberg, J., Grommon, E., Huebner, B. M., \& Bynum, T. (2014). The effect of statewide residency restrictions on sex offender post-release housing mobility. Justice Quarterly, $31(2), 421-444$. 


\section{THE EFFECT OF STATEWIDE RESIDENCY RESTRICTIONS ON SEX OFFENDER POST-RELEASE HOUSING MOBILITY}

A salient theme in the prisoner reentry literature is the enduring challenge of securing stable housing (Morani, Wikoff, Linhorst, \& Bratton, 2011). Parolees face a variety of barriers to housing. Factors such as length of incarceration, loss of social and economic capital, and the stigma associated with a criminal record have been shown to impose considerable obstacles (Pager, 2007, Roman, 2004). Sex offenders face additional challenges in securing stable housing following release from prison (Center for Sex Offender Management, 2007; Hipp, Turner, \& Janetta, 2010). In particular, sex offenders in many states are subject to specialized legislation that restricts housing opportunities.

Within the past 15 years there has been a revival of legislation designed for the postrelease containment and control of sex offenders including sex offender registries, community notification requirements, and residency restrictions (Zgoba, Levenson, \& McKee, 2009). Among the most preventative of legislative tools, residency restrictions place boundaries around areas where children often congregate - such as schools, daycare centers, and parks - which preclude registered sex offenders from living, working, or congregating within those boundaries (Nieto \& Jung, 2006). Recent research has called the efficacy of these restrictions into question (Barnes et al., 2009; Meloy, Miller, \& Curtis, 2008), and indicated that they may produce collateral consequences such as housing instability, transience, and homelessness (Levenson \& Hern, 2007; Tewksbury, 2007).

As such, we consider if sex offenders released under state residency restriction legislation move more often than those who were paroled prior to their implementation, and describe factors associated with varying degrees of housing mobility. We utilize data gleaned from a large sample of sex offenders paroled in a Midwestern state to address these questions. The present 
study attempts to build upon current knowledge on the efficacy of residency restrictions. Several socio-legal reviews of the theoretical underpinnings of residency restriction legislation have been conducted (Meloy et al., 2008; Socia, 2011; Socia \& Stamatel, 2010), yet few studies have considered factors associated with frequency of housing movement among sex offenders following implementation of residency restrictions. This topic is particularly important to scholars and practitioners alike as there is ample evidence that housing instability can reduce the efficacy of treatment (Nelson, Deess, \& Allen 1999) and increase the likelihood of recidivism (Steiner, Makarios and Travis, forthcoming).

\section{Theoretical Background}

Scholars agree that acquiring stable housing is a cornerstone of successful reentry (Metraux \& Culhane, 2004; Schulenberg, 2007; Visher \& Courtney, 2007). In a recent study of a pre-release program, nearly 90 percent of clients identified housing as a critical need (Morani et al., 2011). Although little research has been conducted on parolee residential movement, there is ample theoretical research to suggest that frequent housing transitions may have implications for post-release integration. First, housing mobility can disrupt social networks and undermine social capital (Hagan et al., 1996; Magdol \& Bessel, 2003; South \& Haynie, 2004). Sampson and colleagues (1997) note that developing social networks takes time, and frequent housing moves could perpetually interrupt attempts to build social capital, frustrating attempts at successful reintegration. Frequent moves may enhance the loss of relationships can occur during incarceration. For example, Visher and Courtney (2007) found that while nearly half (46\%) of their sample were living with a spouse or intimate partner prior to incarceration, only 33 percent were doing so one year after their release. 
Stable housing forms the foundation to make gains in other salient reentry dimensions such as employment and treatment (Grommon, 2010), and frequent moves may destabilize reentry transitions increasing the probability of failure, as has been demonstrated with a sample of female parolees and probationers (Morash, 2010). For instance, researchers at the Vera Institute of Justice found that when returning offenders were unable to stay with family or friends immediately following their release, they were required to stay in homeless shelters making refraining from drug-use difficult (Nelson et al., 1999; Gowan, 2002). Correctional personnel also indicate that stable living arrangements can allow parolees to focus on other reentry concerns, such as locating employment (Visher and Farrell, 2005). In short, housing mobility can remove inhibitors to criminal behavior and disrupt the accumulation of social bonds that would facilitate positive reentry transitions.

Returning offenders face significant hurdles securing stable housing. Most parolees arrange to stay with family or friends as a part of pre-release planning but many arrangements are not permanent (Visher et al., 2004). Others live in transitional facilities such as hotels, halfway houses or homeless shelters Parolees also often face economic challenges. Many individuals do not have the economic capital to afford a security deposit on a residence in the private market, thus eliminating the vast majority of housing options (Travis, Solomon, \& Waul, 2001). Legal restrictions further restrict the public housing options available to some felons (Petersilia, 1999). Parole conditions may impede attempts to live with family, given that some of their relatives may have criminal records, live with small children, or be victims of the offender themselves (Visher \& Courtney, 2007). Finally, discrimination emanating from the stigma associated with a criminal record may impose obstacles to securing housing (Pager, 2007). 


\section{Literature Review}

There is ample evidence to suggest that offenders face challenges finding housing, but the evidence on the frequency of movement is mixed. Visher and colleagues (2010) report that within seven months of release 25 percent of their sample had lived in two locations and 10 percent had moved three or more times. Moreover, nearly half of the sample anticipated an imminent residence change. Visher and Courtney (2007) found that among their sample from Cleveland, one-third (37\%) did not move within the first year, while the remaining 63 percent moved at least once, with 29 percent moving three or more times. Most recently Steiner and colleagues (forthcoming) reported that more than half of the offenders in their sample moved at least once in the course of a year.

There is little empirical research on the effect of residential movement on recidivism. Scally and Newman (2003) observe that unaddressed housing instability among returning offenders does little to break cycles of offending and may present a public safety risk. Indeed, Meredith, Speir, and Johnson (2007) found that each address change made by a parolee increased the likelihood of rearrest by 25 percent. Most recently, Makarios, Steiner, and Travis (2010) and Steiner, Makarios and Travis (forthcoming) also found a positive relationship between frequent residential changes and the probability of rearrest, net of other factors. Conversely, LaVigne and Parthasarathy (2005) found that there were no differences in reentry outcomes between those who stayed at a single address for their parole and those that moved. In fact, they noted that returning offenders who moved did so as a reflection of their increased independence, as opposed to being a sign of instability.

One factor that has been posited to complicate the post-release housing experiences of sex offenders is the implementation of residency restrictions. Researchers have begun to explore 
the implications of these policies on post-release housing among sex offender samples. While there is little doubt that residency restrictions were imposed with the goal of protecting children and promoting public safety through the neutralization of sex offender risk (Simon, 1998; Levenson \& Cotter, 2005), little research has evaluated the extent to which residency restrictions accomplish these goals (see Levenson, Zgoba, \& Tewksbury, 2007; Socia \& Stamatel, 2010; Socia, 2011). Most of the current research has examined the collateral consequences of residency restrictions on the post-release experiences of returning sex offenders (Mercado, Alvarez, \& Levenson, 2008). The research is geographic in nature and has attempted to forecast the effect of jurisdictions adopting residency restrictions on the housing options for the sex offenders living there or returning to those communities from prison. Relevant to the concerns of housing mobility, several studies found that adopting boundary zones around places like schools, daycares, parks, and bus stops severely restricts available housing (Zandbergen \& Hart, 2006; Barnes et al., 2009; Chajewski \& Mercado, 2009; Zgoba et al., 2009). Most recently, Socia (2011), in his research in New York State, found that as the scope of the residency restriction grows, the availability of housing is reduced. After restrictions were put in place, the neighborhoods with the least amount of restricted housing were typically less dense, less affordable, and had less housing available for purchase or rent. Socia (2011) also noted that unrestricted neighborhoods for sex offenders showed less social disorganization. This particular finding was contrary to that of Hughes and Burchfield (2008), who found that Chicago's residency restriction law tended to funnel sex offenders into disadvantaged areas.

Another group of spatially-oriented inquiries examine the characteristics of sex offenders' residences. Mustaine and colleagues (2006) found that the sex offenders who lived in less socially disorganized areas prior to their arrest were more likely to move to a more socially 
disorganized area after registering as a sex offender. In a more recent inquiry, Hipp and colleagues (2010) note that relative to other offenders, sex offenders were significantly more likely to be released into neighborhoods with higher degrees of social disorganization and subsequent moves by sex offenders were to more disorganized areas.

A number of qualitative studies have documented the effect of residency restrictions on parolee's experiences in the community. Sex offenders report having to live farther away from sources of social support like family or friends as a result of residency restrictions (Levenson \& Cotter, 2005; Levenson \& Hern, 2007; Levenson, 2008; Mercado et al., 2008). Levenson and Tewksbury (2009) interviewed the family members of 584 registered sex offenders and 30 percent of respondents reported residency restrictions precluded offenders from living with family. Some sex offenders reported not being able to return to a home that they previously owned or rented, and having to move as a result of residency restrictions (Levenson \& Cotter, 2005; Levenson \& Hern, 2007; Levenson, 2008). For example seven percent of a sample released in Indiana moved because of residency restrictions (Levenson \& Hern, 2007); whereas, 22 percent of a similar sample in Florida reported residential moves (Levenson, 2008). The proportions were consistently higher for those who reported having to move out of a home they rented. In addition, Levenson, D’Amora, \& Hern, (2007) found that some sex offenders reported having to move because a landlord (10\%) or neighbor $(8 \%)$ found out they were a sex offender. These findings are consistent with the notion that residency restrictions disrupt social capital resources by denying sex offenders access to intact social networks.

The implications of the extant research on residency restrictions remain ambiguous. To date, only one study has considered offender housing movement following the enactment of residency restriction legislation. Utilizing a post-only research design, Levenson (2008) reported 
that half of her purposive sample of sex offenders in outpatient treatment (47\%) did not report moving at all since release, while one-fifth (22\%) reported moving three or more times. The frequency of movement was higher for younger offenders, but was unrelated to years of education, income, or the size of the residency restriction buffer zone. Additional quasiexperimental studies are necessary to determine the impact of residence restrictions on the postrelease housing mobility of sex offender populations.

\section{The Present Inquiry}

The goal of this analysis is twofold. First, we consider if sex offenders paroled after the implementation of statewide residency restrictions move more often than those released prior to implementation. Next, we document the individual-level factors associated with housing mobility. The current study utilizes a quasi-experimental cohort control group design (Shadish, Cook, \& Campbell, 2002) where a sample of sex offenders paroled prior to the start of residency restrictions compromises a control group and a sample of sex offenders paroled after the implementation represents the intervention group.

Residency restrictions took effect in the study state on January $1^{\text {st }}, 2006$ and impose a 1,000 foot buffer zone around schools and a 500 foot buffer zone around parks. ${ }^{1}$ Registered sex offenders are precluded from living, working, or loitering within the zone created by the boundary zone. ${ }^{2}$ Interviews with State Police and Department of Corrections staff indicated that there was some lag in the implementation of residency restrictions; therefore, we use the date of June $30^{\text {th }}, 2006$ as the implementation date. The pre-restriction sample of parolees included

\footnotetext{
${ }^{1}$ Schools include any building (public or private) used to educate children under age 19. Although some states have local towns that enact stricter boundary zones than the statewide law (Meloy et al, 2008), there are no local enhancements in the study state.

${ }^{2}$ As an exception, there is a grandfather clause whereby those who were already living or working within the boundary are not required to move. However, if an offender moves they must comply with the restrictions law.
} 
registered sex offenders paroled between the dates of January $1^{\text {st }}, 2003$ and June $30^{\text {th }}, 2006$. The restriction sample included registered sex offenders paroled between the dates of July $1^{\text {st }}, 2006$ and December $31^{\text {st }}, 2007$. The cut-off date for the restriction sample was constrained in order to allow for at least two years of observation, which attempts to equate their time at risk while on parole with the pre-restriction group. The final sample consists of 1,936 male sex offenders including 1,518 who were paroled in the pre-residency restriction group and 418 paroled in the post-restriction group. ${ }^{3}$ Both groups were required to meet state registration requirements. ${ }^{4}$

Address, demographic, and criminal history data were obtained from the state Department of Corrections. Address data included street number, street name, city, zipcode, and move-in date information. All data were maintained by parole officers. As part of data cleaning, these address data were geocoded to address points using ArcGIS ArcMap version 9.1. ${ }^{5}$

Dependent variable. The dependent measure is the total number of residential address changes made by the offender. Data were culled from official Department of Corrections data. Move zero was defined as the initial parolee address. Offenders who were paroled and then moved one time would be coded as " 1 " and so forth. The number of moves ranged from 0 to 14 ,

\footnotetext{
${ }^{3}$ The study state uses a tiered sexual offense classification system based upon contact circumstances. The most serious categories involve sexual penetration or contact with additional conditions of young victim age, coercion, or injury. Less serious categories involve sexual penetration or contact in the absence of aggravating circumstances. Non-contact offenders convicted of gross indecency, child pornography, and computer-based indecency or pornography offenses were excluded from the sample. For our final sample, 46.7\% $(\mathrm{N}=905)$ fell into the more serious contact categories, $42.8 \%(\mathrm{~N}=828)$ fell into the less serious contact categories, and the remaining $10.5 \%(\mathrm{~N}$ $=203$ ) had committed an assault with intent to commit a contact sexual offense.

${ }^{4}$ Sex offenders must register and report in-person to a law enforcement agency to verify home address and provide information on education, employment, transportation, and communication activities. Offenders in both groups are not allowed to live in a residence with children under the age of 18 including their own children.

${ }^{5}$ The analyses here represent a subsample taken from a larger sample of sex offenders. Geocoding was initially performed on the larger sample and the subsample was derived after the geocoding process was complete. A minimum match criteria of $60 \%$ was used and those that were not automatically matched were attempted to be matched interactively. Out of 8,374total addresses, 7,416 (88.6\%) were successfully matched at a score of 80 to 100 , $462(5.5 \%)$ were matched with a score lower than $80,391(4.7 \%)$ could not be matched to an address point and had to instead be matched to a zipcode centroid, and $105(1.2 \%)$ could not be matched either because they corresponded to an out of state address or no match could be made interactively.
} 
with an average of 1.93 moves. Approximately $72 \%$ of the sample $(\mathrm{N}=1,389)$ moved at least once in the time between release from prison and termination of supervision. Our sample had more housing mobility compared to other studies of this type (e.g. Levenson, 2008; Visher \& Farrell, 2005; Visher \& Courtney, 2007).

Housing is central to discussions of reentry, but housing mobility has been underresearched as an outcome of post-release experiences in the community. Dichotomous indicators of movement against non-movement have been used to describe mobility patterns among generalized samples (e.g., La Vigne \& Parsatharathy [2005] discussion of movers and stayers). Continuous measures of mobility have also been used as predictors of recidivism (Steiner, Makarios, \& Travis, forthcoming). There is some evidence to suggest that low levels of mobility - such as one or two moves within a short time frame - may not be indicative of post-release instability (Grommon et al., 2011; LaVigne \& Parthasarathy, 2005; Lutze, Bouffard, \& Rosky, 2010). We transformed the raw moves variable into a four category ordinal measure $(0=$ no residential moves, $1=1-2$ moves, $2=3-4$ moves, $3=5+$ moves). Such a measure allows for a better examination of differing degrees of housing mobility and is consistent with literature that suggests movement may commonly be at the extremes (see Levenson, 2008). Indeed, while moving one or two times following release from prison may not be an indication of post-release instability (e.g., LaVigne \& Parthasarathy, 2005), those who move five or more times may present themselves as qualitatively different category of individuals (Morash, 2010). Additional benefits of the transformation include the correction of extreme mobility outliers and modeling of cases with no residential moves.

Independent variables. We include three groupings of independent variables in our analyses, see Table 1 for a complete listing of descriptive statistics. The first of these groups 
corresponds to conditions of parole, and were developed using official Department of

Corrections data. Two dichotomous measures denote if the sex offender was released under

residency restrictions and thus were subject to a restriction parole $(1=$ yes, $0=$ no $)$ and also if he paroled to a non-residential address $(1=$ commercial placement, transitional housing, treatment facilities, or correctional facilities, $0=$ residential addresses). ${ }^{6}$ The non-residential parole address is an indication that the sex offender's parole move (i.e. move zero) was to a location other than a residential address. ${ }^{7}$ The variable is used to control for housing mobility estimates that may be confounded by residence at a temporary location where a subsequent change in address is expected. Approximately one-fifth of the sample (17.7\%) was paroled to a non-residential location. Also included is the length of the incarceration for which the sex offender is currently on parole. We anticipate that sex offenders with lengthy incarcerations will show higher degrees of housing mobility due to the negative impact of incarceration length on social capital (DeJong, 1997).

The second grouping of independent variables captures demographic controls. We incorporate indicators of age at time of parole (in years), racelethnicity (non-white $=1$ ), education (less than high school diploma as reference category), and marital status (ever married $=1) .{ }^{8}$ In addition there are assault and property risk assessments which characterize the sex offender as low, medium, or high risk of recidivism and non-compliance through a variant of a

\footnotetext{
${ }^{6}$ To add further clarity regarding the conceptualization of non-residential terms, "commercial placement" refers to initial placements to hotels, motels, and shelters. "Transitional housing" represents initial placements to semi-secure, shared residences that provide transitional services. "Treatment facilities" correspond to initial placements to inpatient centers for treatment of sexual and/or drug use behaviors. "Correctional facilities" refer to secure Department of Corrections' facilities that are used to provide offenders with treatment services that were required, but not completed while the offender was in an institution or aftercare services.

${ }^{7}$ We were able to glean the non-residential parole variable from our data using triangulation. The address data indicated that particular addresses were something other than a residential address, such as hotels, motels, treatment facilities, or correctional facilities. This was determined by review of qualitative agent case notes and subsequent online queries. A limitation is that the parole agent case notes are often incomplete, and in the absence of any indication from case notes or internet queries, we assume the address was a residential location.

${ }^{8}$ While it would be ideal to disaggregate the non-white variable into racial/ethnic categories and also consider gender in the present analysis, the sample included very small numbers of Hispanic and female sex offenders.
} 
salient factor scores (Hoffman \& Beck, 1974). Items are largely driven by criminal history and instance offense information. Medium risk offenders were used as the reference category because of low numbers of low or high risk offenders in either the property or assault risk variables, and to maintain consistency of interpretation. ${ }^{9}$ We also include an indicator of whether the sex offender was a child molester, being on parole for committing a sex offense against a victim under the age of 13 ( $1=$ was under the age of 13 years, $0=$ victim 13 or older).

The final grouping of independent variables captures the criminal history of each of the sex offenders in the sample. These variables indicate whether the individual's criminal history includes convictions for drug, violent, property, or public safety offenses (e.g., weapons offenses, flee or escape from law enforcement, unlawful motor vehicle offenses). This measure is used to gauge specialization or generalization of offense patterns. Every sex offender in the sample committed a contact sex offense, and therefore has at least one sex offense on their history. The majority of the sample is comprised of individuals whose criminal history only includes sex offenses (73.6\%). Of those whose history only includes sex offenses, $21.7 \%$ were convicted of multiple sex offenses while $78.3 \%$ were convicted of one sex offense and have no other criminal history. The remainder of the sample (24.6\%) committed at least one sex offense plus at least one non-sexual offense. In the multivariate analyses those sex offenders with only sex offense convictions in their history comprise the reference category.

Finally, length of time on parole serves as a control variable, which reflects the duration between the offender's parole date and the termination of supervision (i.e., the variable corresponds to the length of the sex offender's supervision). Ideally both the pre-restriction and restriction groups would serve identical lengths of time on parole. Indeed, parole length could

\footnotetext{
${ }^{9}$ The Department of Corrections utilizes an internal salient factor score risk assessment of assault and property crime risk. The research team only had access to summary risk scores. The majority of risk assessments (70\%) were administered at intake, but some were calculated following the offender's release from prison.
} 
potentially be an intervening variable in the relationship between residency restrictions and housing mobility, whereas longer periods on parole give more opportunities to move. Because the difference in length of time on parole for the pre-restriction and restrictions group is statistically significant (see Table 1), we ward against spuriousness by controlling for it in the multivariate analysis.

\section{Results}

\section{Bivariate Analyses}

First, we utilize bivariate mean difference tests to consider if sex offenders released under residency restrictions move more often than those released prior to their implementation. As displayed in Table 1, sex offenders move about two times over the course of their supervision term. Sex offenders paroled in the residency restriction group have significantly more address moves than those paroled prior to their implementation $(t(1,934)=-2.61, \mathrm{p}<.01)$

\section{[Table 1 about here]}

A few other differences emerged. The largest difference between the two groups is time on parole. Individuals in the pre-restriction group were on parole for an average of 905.62 days, and the restriction group was on parole for 632.16 days on average $(t(1,369)=20.42, \mathrm{p}<.001) .{ }^{10}$ In addition, a significantly smaller proportion of the restriction offenders were married at some point $(t(674)=2.61, \mathrm{p}<.01)$, and a larger proportion had not finished their high school diploma $(t(684)=-2.30, \mathrm{p}<.05)$ relative to the pre-restriction group. In terms of criminal history, there was a significantly smaller proportion of sex offender specialists (individuals with only sex

\footnotetext{
${ }^{10}$ We considered restricting the sample to those offenders with 400 to 800 days on parole in order to make the groups more equitable. Restricting the sample did not change the bivariate relationship between residency restrictions and mobility; therefore, the larger sample was used and conservative estimates provided. An additional concern is that the significant differences in time at risk between the pre-restriction and postrestriction groups. Residential mobility is truncated for those who are returned to prison. Supplementary analyses (not shown) show no significant differences $\left(\chi^{2}(1)=2.33, \mathrm{p}=.311\right.$ ) in recidivism between restriction groups.
} 
offenses in their criminal history) in the restriction group $(t(632)=2.38, \mathrm{p}<.05)$, and a significantly larger proportion of individuals with a history of public safety offenses $(t(578)=-$ $2.62, \mathrm{p}<.05)$ relative to the pre-restriction group. Otherwise, the pre-restriction and restriction groups do not differ significantly.

Next, we consider the factors associated with varying degrees of housing mobility. To begin to answer this question we utilize an ordinal measure of housing mobility with categories of zero, one to two, three to four, and five or more address moves and compare the values of our independent variables across these categories using ANOVA. The statistical significance of differences across categories is determined using Bonferroni post-hoc tests. The results of this analysis are presented in Table 2 .

\section{[Table 2 about here]}

There are several factors that differentiate degrees of housing mobility. Among the mobility groups, those with three to four moves had the largest proportion of sex offenders paroled under residency restrictions, and the zero moves group had the fewest offenders in the restriction group.

There were also large differences between the lowest and highest mobility groups in regards to non-residential parole locations. Of those who did not move at all following their release only nine percent were paroled to a non-residential location, while 26 percent of sex offenders that moved five or more times were paroled to such locations. The effect is in the opposite direction for length of incarceration. The groups with the lowest degrees of mobility served significantly longer sentences than the high mobility groups. This runs contrary to our prediction that longer stays of incarceration would result in higher degrees of housing mobility following release. 
Moving on to demographic characteristics, particular variables showed significant differentiation across groups. Notably, the average age of sex offenders in the low mobility groups was relatively higher than in the high mobility groups. In other words, sex offenders that did not move at all or one or twice following their release were significantly older than those who moved three or four, or five or more times. In regards to race, the high mobility groups had significantly larger proportions of non-white offenders relative to the low mobility groups, indicating that non-white sex offenders are more likely to show a high degree of mobility following their release. Education level was also key to differentiating mobility groups. The higher mobility groups were more likely to be made up of sex offenders without high school diplomas.

Criminal history variables did little to differentiate groups. The highest mobility group had significantly lower proportion of parolees with only sex offenses in their criminal history and a higher proportion of sex offenders with a history of public safety offenses, relative to the lowest mobility group. Additionally, the mobility groups differed in the proportion of child molesters. These offenders were significantly more likely to belong to a low mobility group with one to two moves or a high mobility group with five or more moves over three or four moves.

Lastly, we examined length of time spent on parole. As anticipated, higher mobility groups spent longer periods on parole than the lower mobility groups. This is primarily due to the fact that they had a longer time to move or their movement was not due to incarceration.

\section{Multivariate Analysis}

Next, a series of multinomial logistic regression models were analyzed (Long, 1997). ${ }^{11}$ Sex offenders with zero moves serve as the reference category and each set of coefficients

\footnotetext{
${ }^{11}$ In our initial analyses, we considered several other models including ordinal logistic, Poisson, and negative binomial regression. The proportional odds assumption test of the ordinal logistic regression model was violated and
} 
displays the effect of the independent variable on the odds of a sex offender belonging to the indicated mobility group (i.e., one to two, three to four, or five or more moves) versus the zero address moves group. Results are presented in Table $3 .^{12}$

\section{[Table 3 about here]}

The first set of regression coefficients in Table 3 corresponds to the effect of the independent variables on the odds of the sex offenders in our sample having one or two address moves following their release as opposed to zero. There are few significant differences. Sex offenders paroled to non-residential locations are significantly more likely to have one or two moves relative to those paroled to residential addresses (odds ratio $=2.36$ ). In addition, sex offenders who completed high school were significantly less likely to move one or two times as opposed to zero times, relative to those without a high school diploma (odds ratio $=0.61$ ).

More pronounced differences emerge in the contrasts between the higher mobility groups and the zero moves group. Sex offenders paroled under residency restrictions were significantly more likely to have three to four (odds ratio $=1.98$ ) or five or more moves (odds ratio $=1.87$ ) than zero moves, relative to those sex offenders paroled in the pre-restriction group. A similar effect emerges for sex offenders paroled to non-residential locations, as those offenders had increased odds of moving three to four (odds ratio $=3.48$ ), or five or more times (odds ratio $=$ 3.81) compared to sex offenders paroled to residential addresses. Length of incarceration was a significant point of differentiation between the five or more moves group and the zero moves

the Poisson regression suffered from overdispersion. As such, the estimates derived from these models are biased and not used in this study. A two phase negative binomial regression analysis was used to confirm the results. First, predictors used in the multinomial logistic model were used in the negative binomial model. Second, the time at risk measure in the multinomial logistic model was dropped from the negative binomial model and an alternative measure was used. All of the remaining predictors used in the multinomial logistic model were added to the negative binomial model. The alternative measure transformed the raw count of days at risk into an offset rate variable $[\log ($ parole length+.0001) $]$ and was entered as a predictor (Maddala, 1983). The findings for this model were consistent with the multinomial logistic regression model.

${ }^{12}$ Collinearity diagnostics (variance inflation factors and tolerance) were performed and did not suggest any concerns with model fit. 
group. More specifically, the longer the sex offender's most recent incarceration, the lower the odds of moving five or more times as opposed to zero times.

There were several demographic characteristics that differentiated mobility groups. Older offenders and those with educational experience beyond high school were significantly less likely to show high degrees of mobility, relative to younger offenders and those without a high school diploma. Non-white parolees were more likely to move three to four times (odds ratio $=$ 1.44) relative to white sex offenders and even higher chances of moving five or more times (odds ratio $=1.85)$

There were conflicting effects for the risk measures, whereas sex offenders with low assault risk were significantly more likely to show a high degree of mobility compared to medium risk offenders (odds ratio $=4.51$ ), and low property risk offenders were significantly less likely than medium risk offenders to do the same (odds ratio $=0.62$ ). Interestingly, while child molesters were no more likely than all other sex offenders to move one to two, or three to four times as opposed to zero times, they were significantly more likely to move upwards of five times following their release (odds ratio $=1.83$ ). Finally, criminal history did not appear to be significantly related to housing mobility as only those sex offenders with a history of public safety offenses were more likely than sex offender specialists to move five or more times as opposed to zero times.

\section{Discussion}

This study sought to answer two research questions. First, do sex offenders released under state residency restriction legislation move more than similarly situated sex offenders paroled prior to implementation? The results of the pre-post cohort control quasi-experimental analysis suggest that sex offenders paroled under residency restriction legislation move more 
often than offenders paroled prior to the implementation. In fact, sex offenders paroled under residency restrictions were nearly two times more likely to have three or more residential moves than to remain stable, relative to those sex offenders paroled in the pre-restriction group. In addition, the total sample had higher rates of mobility seen when compared to a general offender population of parolees released in Chicago (LaVigne \& Parthasarathy, 2005) and a sample of sex offenders in Florida (Levenson, 2008). Low levels of residential movement, as defined by one to two moves, appeared to overlap between the groups and suggest that some level of movement amongst sex offenders is to be expected during the process of transition to the community. This finding consistent with research conducted using general parolee samples (Visher, Yahner, \& La Vigne, 2010).

Residential movement is important for a number of reasons. First, research suggests that mobility can undermine social capital (Sampson, Raudenbush, \& Earls, 1997; Visher and Travis, 2003). The lack of stability and structure may strain relationships (National Research Council, 2008; Roman \& Travis, 2004), subsequently hamper attempts at behavioral change (Grommon et al., 2011) and increase the risk of recidivism (Nelson et al., 1999). Parolees rely heavily on social networks for initial housing and employment opportunities, and to this extent some are able to draw upon their social capital resources in order to facilitate successful reintegration (Nelson et al., 1999; Berg \& Huebner, 2011; Cobbina, Huebner, \& Berg, Forthcoming).

From a management perspective, residential movement requires enhances supervision from parole staff who already contribute significant resources to the surveillance of current sex offender residences. In the study state, each move requires a new home plan which involves a site investigation and approval by parole officials. Frequent movement may increase workloads 
for parole officers with sex offender caseloads and could compromise surveillance efforts. From a routine activities perspective, housing changes may also hamper transportation.

The second goal of the project was to document the individual-level factors associated with housing mobility. Most relevant to residency restriction legislation is the observation that offenders convicted of sex offenses against victims under the age of 13 experienced the highest rate of residential movement. Child molesters were significantly more likely to be in the highest movement group than to be in the zero movement group, and this pattern emerged in the pre and post samples. As child molesters are the central target of sex offender legislation (Sample \& Bray, 2006), the high mobility among this group raises concerns for post-release rehabilitation and surveillance.

Additional analyses were conducted to explore the unique movement patterns among child molesters. In the supplementation analysis, (not shown) we regressed the interaction of residency restriction terms and the child molester variable on residential movement. The interaction effects were mixed. The results suggest that offenders who committed crimes against young children were more likely to move five or more times relative to zero times, but the effect was largely confined to the pre-restriction period. Those child molesters released during residence restrictions were more likely to experience no further residential movement relative to the potential to move three to four times. These trends suggest that individuals convicted of child molestation experience housing movement on the extremes - largely stable with no further movement or largely unstable with relatively high movement. Moreover, these trends may lend some support to the notion that residency restrictions may limit residential movement for this type of offender. However, it is still not clear if such limited movement is due to choice, coercion, or non-compliance with community supervision that does not lead to reincarceration. 
Future research will benefit from the continued exploration into the potential for interactive effects.

In addition, offenders who were released to a non-residential parole placement had significantly more moves relative to those who returned to residential addresses. ${ }^{13}$ In the study state, transitional facilities are used for offenders who do not have a suitable home plan or do not have housing support from others. The nature of transitional housing available depends upon the community to which the sex offender is paroled, as some have dedicated treatment facilities, while others utilize contracts with local motels. High levels of movement may also reflect selection as individuals with less social support are more likely to live in transitional housing (Nelson et al., 1999). The sex offense conviction can further reduce options, as residence with family members or friends is not allowed if youth are also residing in the home (Levenson \& Cotter, 2005).

If non-residential placement is necessary, effort must be made to maintain housing stability. Ideally, housing placement would be determined during the pre-release process in an effort to secure alternative housing if the specified placement is within boundary restriction zones. Pre-release planning is not always feasible and many offenders are subject to the cycle of obtaining, losing, and gaining housing (Levenson \& Hern, 2007). In some situations the public has made active decisions to locate new schools, parks, and daycare centers in strategic areas with the goal of deterring housing for potential offenders who may move to the area (Burchfield \& Mingus, 2008). There are also challenges to providing transitional housing. Non-residential

\footnotetext{
${ }^{13}$ We used an alternative non-residential variable to explore the sensitivity of the finding. The alternative categorical measure contrasted residential placement (0) against commercial (1) and correctional or coerced (2) placement, which includes residence at halfway houses, treatment facilities, or correctional facilities. On average, correctional or coerced placement had the highest rate of movement $(M=2.81 S D=2.36)$ and was followed by commercial $(M=2.56 S D=2.15)$ and residential $(M=1.69 S D=1.95)$. Multivariate modeling with the alternative measure produced similar estimates to the original measure and confirmed the findings of the research.
} 
placement providers may be available in some locations but not others (Roman \& Travis, 2004). Intake policies can systematically limit placement availability, and providers can limit length of stay. Partnership and planning between community supervision agencies, non-residential placement providers, and offenders is necessary. In many instances, pre-existing partnerships exist through referral networks (Seiter, 2002). What is needed is coordinated partnership and planning within established referral networks. Growing evidence suggest that enhanced case management approaches can increase access to community resources (English, Pullen, \& Jones, 1997; Minnesota Department of Corrections, 2010; Rossman \& Roman, 2003; Zhang, Roberts, \& Callanan, 2006), and it is likely that such access would translate to progress in managing reentry challenges.

Informed policy should also consider the variability in offenders and sexual behaviors. Child molesters had the highest degree of residential movement; this group also had lower rates of movement following the implementation of residency restrictions. At the same time, the legislation increased residential movement for any other contact sexual offender. As such, the broad scope of the legislation appears have differential effects on sub-populations of sex offenders. The results of this research highlight the need for sex offender specific models. Members of the current sample came to prison with less developed criminal histories, and sex offenders are traditionally older than other offenders. There is evidence that sex offender populations may lead a life of relative normalcy in conventional society and gain social capital (Levenson \& Tewksbury, 2009); therefore, future legislation may want to consider the heterogeneity of sex offender behaviors.

Risk instruments may be useful in differentiating sex offenders, with certain caveats. Actuarial tools often focus on the likelihood ratios of recidivism and non-compliance. This is 
especially true for risk assessments that are based upon variants of salient factor scores (Hoffman \& Beck, 1974), which form the background for the risk measures in the present analysis. Such instruments may not be valid to the determination of housing mobility. Moreover, salient factor scores are generalized assessments and may not inform sex offender risk (Hoffman \& Beck, 1974). Assessments geared towards sex offender populations (e.g., static-99) may be more suitable, but still focus on recidivist dimensions and risk.

Despite the unique research findings, several study limitations remain. First, as with any non-randomized quasi-experimental study there is a potential for sample selection bias. Our results showed that the restriction groups were significantly different on several variables that may confound housing mobility differences, including the length of time spent on parole. The research design does not allow us to achieve a true counterfactual, potentially rendering housing mobility patterns in either the control or intervention groups as an artifact of these preexisting differences. Instead, our conclusions are drawn from a comparison of a sample of sex offenders paroled prior to the implementation of residency restrictions to a sample paroled after their imposition. We attempted to statistically control for pre-existing differences with multivariate analyses. Multiple checks were conducted to assess the robustness of our results, suggesting that differences in housing mobility between the groups were not an artifact of pre-existing differences in the observed covariates.

Second, and similar to research of this type, the study relies on official administrative data. Many of the variables analyzed were constructed using data that were gathered by parole agents and entered into Department of Corrections databases. The accuracy of these data is contingent on the diligence of the parole agents responsible for its maintenance. One variable that would be particularly vulnerable to inaccuracies is the non-residential parole address, which 
was initially identified via parole agent case notes. The validity of this measure was subsequently improved via triangulation with the notes of other parole agents and internet queries of the addresses in question. With these limitations in mind, the estimates of housing movement may be downwardly biased and thereby conservative. At the same time, our confidence in the number of residential changes is strong. Similar to other states (see Steiner et al., forthcoming), knowledge of address changes are a high priority for parole agents and the documentation of movement in management information systems is assumed to be reliable and complete.

Similarly, there is the potential for history to provide a threat to internal validity. The analyses above suggested that sex offenders paroled after the implementation of residency restrictions moved more often than sex offenders paroled prior to their implementation. While this suggests that the significantly different movement frequency between the groups is at least partially due to the residency restrictions, there is the possibility that the residency restriction law led parole agents to maintain stricter records of movements, similar to the manner in which intensive supervision practices have been shown to lead to increased arrests (Petersilia \& Turner, 1993). Despite these possibilities for bias to exist in the data, there is little reason to suspect systematic bias in the parole records contaminated our analyses. Ethnographic research on parole agents has shown that they tend to keep particularly stringent records on sex offenders in their caseloads because of their perceived high risk potential and public scrutiny on the parole office regarding sex offender management (Lynch, 1998; McCleary, 1977).

Finally, we were not able to ascertain the reasons for movement, and we did not evaluate the social context of the residential location. Residential change is not a monolithic experience, but most research has classified moving as a negative event. There is initial evidence that movement can reflect economic or social opportunities for change (Grommon et al., 2011). The 
ability of individuals to draw on resources is not uniformly distributed across the population or social locations. For example, recent evidence suggests that when sex offenders do experience housing mobility, they are more likely to move to socially disorganized areas. Individuals in disorganized areas have less access to transitional resources like treatment (Hipp et al., 2010). Recent research on the Movement to Opportunity experiments further highlights the importance of considering the location of residence (moves within and outside urban areas), local institutional resources, and an individual's perceptions and fear of an environment when estimating models of movement (Sharkey \& Sampson, 2010). The results of the current research suggest that residential change is an important correlate for future investigation; however, more information on the context of the movement event is needed.

In summary, male sex offenders released under residency restrictions in the study state were significantly more likely to move than offenders paroled prior to implementation. The current study reinforces concern that residency restrictions can enhance challenges that are faced during the reentry process by increasing residential movement. A number of questions concerning residency restrictions remain unanswered. It is particularly important to understand why offenders move. It is not clear if relatively high rates of residential movement are area result of limiting enactments, reliance on temporary housing, or enhanced opportunity. In addition, there is little understanding of how the legislation is interpreted and integrated into operations by state and local correctional and law enforcement agencies. Moreover, there is modest documentation of how such conditions are managed by offenders who are subject to the conditions on an everyday basis. Sound research can help future development and modification of residency restriction legislation and policy. 


\section{References}

Barnes, J. C., Dukes T., Tewksbury, T., \& De Troye, T. M. (2009). Analyzing the impact of a statewide residence restriction law on South Carolina sex offenders. Criminal Justice Policy Review, 20(1), 21-43.

Berg, M. T. \& Huebner, B. M. (2011). Reentry and the ties that bind: An examination of social ties, employment, and recidivism. Justice Quarterly, 28(2), 382-410.

Burchfield, K. B. \& Mingus, W. (2008). Not in my neighborhood: Assessing registered sex offenders' experiences with local social capital and social control. Criminal Justice and Behavior, 35(3), 356-374.

Center for Sex Offender Management (2007). Managing the challenges of sex offender reentry. Silver Spring, MD: Author.

Chajewski, M., \& Mercado, C. C. (2009). An evaluation of sex offender residency restriction functioning in town, county, and city-wide jurisdictions. Criminal Justice Policy Review, $20(1), 44-61$.

Cobbina, J. E., Huebner, B. M., \& Berg, M. T. (Forthcoming) Men, women, and postrelease offending: An examination of the nature of the link between relational ties and recidivism Crime \& Delinquency.

DeJong, C. (1997). Specific deterrence and survival analysis: Integrating theoretical and empirical models of recidivism. Criminology 35(4), 561-576.

English, K., Pullen, S. \& Jones, L. (1997). Managing adult sex offenders in the community - A containment approach. Washington, D.C.: National Institute of Justice.

Gowan, T. (2002). The nexus: Homelessness and incarceration in two American cities. Ethnography, 3(4), 500-534.

Grommon, E. (2010). The (in)efficacy of reentry based programs: Exploring the differential effects of prisoner reentry dimensions on outcome indicators. Doctoral Dissertation: Michigan State University.

Grommon, E., Rydberg, J., Onifade, E., Petersen, J., Campbell, C., \& Bynum, T. (2011). The quality and stability of residence after transition into the community. Paper presented at the annual meeting of the Academy of Criminal Justice Sciences, Toronto, Ontario, Canada.

Hagan, J., MacMillan, R., \& Wheaton, B. (1996). New kid in town: Social capital and the life course effects of family migration on children. American Sociological Review, 61(3), 368-385. 
Hipp, J. R., Turner, S., \& Janetta, J. (2010). Are sex offenders moving into social disorganization? Analyzing the residential mobility of California parolees. Journal of Research in Crime and Delinquency, 47(4), 558-590.

Hoffman, P. B. \& Beck, J. L. (1974). Parole decision-making: A salient factor score. Journal of Criminal Justice, 2, 195-206.

Hughes, L. A., \& Burchfield, K. B. (2008). Sex offender residence restrictions in Chicago: An environmental injustice? Justice Quarterly, 25(4), 647-673.

La Vigne, N. \& Parthasarathy, B. (2005). Prisoner reentry and residential mobility. Washington, DC: The Urban Institute.

Levenson, J. S. (2008). Collateral consequences of sex offender residence restrictions. Criminal Justice Studies, 21(2), 153-166.

Levenson, J. S. \& Cotter, L. P. (2005). The Impact of sex offender residence restrictions: 1,000 feet from danger, or one step from absurd? International Journal of Offender Therapy and Comparative Criminology, 49(2), 168-178.

Levenson, J. S., D’Amora, D. A., \& Hern, A. L. (2007). Megan's Law and it's impact on community re-entry for sex offenders. Behavioral Sciences and the Law, 25(4), 587-602.

Levenson, J. S. \& Hern, A. L. (2007). Sex offender residence restrictions: Unintended consequences and community reentry. Justice Research and Policy, 9(1), 59-73.

Levenson, J. S. \& Tewksbury, R. (2009). Collateral damage: Family members of registered sex offenders. American Journal of Criminal Justice, 34(1-2), 54-68.

Levenson, J. S., Zgoba, K. \& Tewksbury, R. (2007). Sex Offender Residence Restrictions: Sensible Crime Policy or Flawed Logic? Federal Probation, 71(3), 2-9.

Long, J. S. (1997). Regression models for categorical and limited dependent variables. Thousand Oaks: Sage.

Lutze, F. E., Bouffard, J., \& Rosky, J. W. (2010). Washington state's reentry housing pilot program evaluation: Year 2 report. Pullman, WA: Washington State University.

Lynch, M. (1998). Waste managers? The new penology, crime fighting, and parole agent identity. Law and Society Review, 32(4), 839-869.

Maddala, G. S. (1983). Limited-dependent and qualitative variables in economics. New York, NY: Cambridge University Press. 
Magdol, L. \& Bessel, D. R. (2003). Social capital, social currency, and portable assets: The impact of residential mobility on exchanges of social support. Personal Relationships, 10(2), 149-169.

Makarios, M., Steiner, B., Travis, L. F. III (2010). Examining the predictors of recidivism among men and women released from prison in Ohio. Criminal Justice and Behavior, 37(12), 1377-1391.

McCleary, R. (1977). How parole officers use records. Social Problems, 24(5), 576-579.

Meloy, M. L., Miller, S., \& Curtis, K. (2008). Making sense out of nonsense: The deconstruction of state-level sex offender residence restrictions. American Journal of Criminal Justice, $33(2), 209-222$.

Mercado, C. C., Alvarez, S., \& Levenson, J. S. (2008). The impact of specialized sex offender legislation on community reentry. Sexual Abuse: A Journal of Research and Treatment 20(2), 188-205.

Meredith, T., Speir, J. C., \& Johnson, S. (2007). Developing and implementing automated risk assessments in parole. Justice Research and Policy, 9(1), 1-24.

Metraux, S. \& Culhane, D. P. (2004). Homeless shelter use and reincarceration following prison release. Criminology \& Public Policy, 3(2), 139-160.

Minnesota Department of Corrections. (2010). An evaluation of the Minnesota Comprehensive Offender Reentry Plan (MCORP): Phase 1 report. St. Paul, MN: Minnesota Department of Corrections.

Morani, N. M., Wikoff, N., Linhorst, D. M., \& Bratton, S. (2011). A description of the selfidentified needs, service expenditures, and social outcomes of participants of a prisoner reentry program. The Prison Journal 91(3), 347-365.

Morash, M. (2010). Women on probation and parole: A feminist critique of community programs and services. Boston, MA: Northeastern University Press.

Mustaine, E. E., Tewksbury, R., \& Stengel, K. M. (2006). Residential location and mobility of registered sex offenders. American Journal of Criminal Justice, 30(2), 177-192.

National Research Council. (2008). Parole, desistance from crime, and community reintegration. Washington, DC: National Academy Press.

Nelson, M., Deess, P., \& Allen, C. (1999). The first month out: Post-incarceration experiences in New York City. New York, NY: Vera Institute of Justice. 
Nieto, M., \& Jung, D. (2006). The impact of residency restrictions on sex offenders and correctional management practices: A literature review (No. CRB 06-008). Sacramento, CA: California Research Bureau.

Pager, D. (2007). Marked: Race, crime, and finding work in an era of mass incarceration. Chicago, IL: University of Chicago Press.

Petersilia, J. (1999). Parole and prisoner reentry in the United States. In (Michael Tonry and Joan Petersilia, eds.) Prisons. Chicago: University of Chicago Press.

Petersilia, J. \& Turner, S. (1993). Evaluating intensive supervision probation/parole: Results of a nationwide experiment. Washington, D.C.: National Institute of Justice.

Roman, C. G. (2004). A roof is not enough: Successful prisoner reintegration requires experimentation and collaboration. Criminology \& Public Policy, 3(2), 161-168.

Roman, C. G., \& Travis, J. (2004). Taking stock: Housing, homelessness, and prisoner reentry. Washington, DC: The Urban Institute.

Rossman, S. B. \& Roman, C. G. (2003). Case-managed reentry and employment: Lessons from the opportunity to succeed program. Justice Research and Policy, 5(2), 75-100.

Sample, L. L. \& Bray, T. M. (2006). Are sex offender different? An examination of rearrest patterns. Criminal Justice Policy Review, 17(1), 83-102.

Sampson, R. J., Raudenbush, S. W., \& Earls, F. (1997). Neighborhoods and violent crime: A multilevel study of collective efficacy. Science, 227, 918-924.

Scally, C. \& Newman, K. (2003). Housing barriers to prisoner reentry in New Jersey. New Brunswick, NJ: New Jersey Institute for Social Justice.

Schulenberg, J. L. (2007). Predicting noncompliant behavior: Disparities in the social locations of male and female probationers. Justice Research and Policy, 9(1), 25-57.

Seiter, R. P. (2002). Prisoner reentry and the role of parole officers. Federal Probation, 66(3), 50-54.

Shadish, W. R., Cook, T. D., \& Campbell, D. T. (2002). Experimental and quasi-experimental designs for generalized causal inference. Boston: Houghton Mifflin Company.

Sharkey, P. \& Sampson, R.J. (2010). Destination effects: Residential mobility and trajectories of adolescent violence in a stratified metropolis. Criminology 48(3),639-682.

Simon, J. (1998). Managing the monstrous: Sex offenders and the new penology. Pyschology, Public Policy, and Law, 4(1/2), 452-457. 
Socia, K. (2011). The policy implications of residence restrictions on sex offender housing in Upstate NY. Criminology \& Public Policy, 10(2), 351-389.

Socia, K. \& Stamatel, J. T. (2010). Assumptions and evidence behind sex offender laws: Registration, community notification, and residence restrictions. Sociology Compass 4(1), $1-20$.

South, S. J. \& Haynie, D. L. (2004). Friendship networks of mobile adolescents. Social Forces, 83(1), 315-350.

Steiner, B., Makarios, M. D., \& Travis, L. F. III (Forthcoming). Examining the effects of residential situations and residential mobility on offender recidivism. Crime \& Delinquency.

Tewksbury, R. (2007). Exile at home: The unintended collateral consequences of sex offender residency restrictions. Harvard Civil Rights-Civil Liberties Law Review, 42, 531-540.

Travis, J., Solomon, A. L., \& Waul, W. (2001). From prison to home: The dimensions and consequences of prisoner reentry. Washington, DC: The Urban Institute.

Visher, C. A. \& Courtney, S. M. E. (2007). One year out: Experiences of prisoners returning to Cleveland. Washington, DC: The Urban Institute.

Visher, C. A., \& Farrell, J. (2005). Chicago communities and prisoner reentry. Washington, DC: The Urban Institute.

Visher, C. A., Kachnowski, V., La Vigne, N., \& Travis, J. (2004). Baltimore prisoners' experiences returning home. Washington, DC: The Urban Institute.

Visher, C. A. \& Travis, J. (2003). Transitions from prison to community: Understanding individual pathways. Annual Review of Sociology, 29, 89-113.

Visher, C. A., Yahner, J., \& La Vigne, N. (2010). Life after prison: Tracking the experiences of male prisoners returning to Chicago, Cleveland, and Houston. Washington, DC: The Urban Institute.

Zandbergen, P. A., \& Hart, T. C. (2006). Reducing housing options for convicted sex offenders: Investigating the impact of residency restriction laws using GIS. Justice Research and Policy, 8(2), 1-24.

Zgoba, K. M., Levenson, J. S., \& McKee, T. (2009). Examining the impact of sex offender residence restrictions on housing availability. Criminal Justice Policy Review, 20(1), 91110.

Zhang, S. X., Roberts, R. E. L., \& Callanan, V. J. (2006). Preventing parolees from returning to prison through community-based reintegration. Crime and Delinquency, 52(4), 551-571. 
Table 1

Descriptive Statistics by Residency Restriction Status $(\mathbf{N}=1,936)$

\begin{tabular}{|c|c|c|c|c|}
\hline \multirow[t]{2}{*}{ Variable } & $\begin{array}{l}\text { Pre-Restriction Parole } \\
(\mathrm{N}=1,518)\end{array}$ & $\begin{array}{l}\text { Restriction Parole } \\
(\mathrm{N}=418)\end{array}$ & $\begin{array}{c}\text { Total Sample } \\
(\mathrm{N}=1,936)\end{array}$ & t-value \\
\hline & $\mathrm{M}(\mathrm{SD})$ & $\mathrm{M}(\mathrm{SD})$ & $\mathrm{M}(\mathrm{SD})$ & \\
\hline \multicolumn{5}{|l|}{ Dependent variable } \\
\hline Total Moves & $1.87(2.02)$ & $2.17(2.23)$ & $1.93(2.07)$ & $-2.61 * *$ \\
\hline \multicolumn{5}{|l|}{ Parole Characteristics } \\
\hline Restriction Parole & -- & -- & $0.22(.41)$ & -- \\
\hline Parole Length (days) & $905.62(376.42)$ & $632.16(189.67)$ & $846.58(362.63)$ & $20.42 * * *$ \\
\hline Non-Residential Placement & $0.17(.38)$ & $0.21(.41)$ & $0.18(.38)$ & -1.69 \\
\hline Length of Incarceration (months) & $76.02(52.87)$ & $71.83(60.68)$ & $75.11(54.66)$ & 1.39 \\
\hline \multicolumn{5}{|l|}{ Offender Demographics } \\
\hline Age at Parole & $37.01(11.10)$ & $36.14(12.36)$ & $36.82(11.38)$ & 1.29 \\
\hline Non-white & $0.32(.47)$ & $0.30(.46)$ & $0.32(.47)$ & 0.68 \\
\hline Ever Married & $0.47(.50)$ & $0.40(.49)$ & $0.46(.50)$ & $2.61 * *$ \\
\hline Less than High School & $0.61(.49)$ & $0.67(.47)$ & $0.62(.48)$ & $-2.30 *$ \\
\hline High School Diploma & $0.30(.46)$ & $0.26(.44)$ & $0.29(.45)$ & 1.51 \\
\hline More than High School Diploma & $0.09(.29)$ & $0.07(.25)$ & $0.09(.28)$ & 1.62 \\
\hline Low Assault Risk & $0.03(.18)$ & $0.02(.14)$ & $0.03(.17)$ & 1.85 \\
\hline Medium Assault Risk & $0.75(.43)$ & $0.77(.42)$ & $0.75(.43)$ & -0.64 \\
\hline High Assault Risk & $0.22(.41)$ & $0.22(.41)$ & $0.22(.41)$ & 0.05 \\
\hline Low Property Risk & $0.65(.48)$ & $0.66(.47)$ & $0.65(.47)$ & -0.47 \\
\hline Medium Property Risk & $0.22(.41)$ & $0.18(.39)$ & $0.21(.41)$ & 1.55 \\
\hline High Property Risk & $0.13(.34)$ & $0.16(.36)$ & $0.14(.35)$ & -1.07 \\
\hline Child Molester & $0.22(.42)$ & $0.24(.43)$ & $0.23(.42)$ & -0.69 \\
\hline \multicolumn{5}{|l|}{ Criminal History } \\
\hline Only Sex Offenses in History & $0.75(.43)$ & $0.69(.46)$ & $0.74(.44)$ & $2.38 *$ \\
\hline History of Drug Offenses & $0.05(.21)$ & $0.07(.25)$ & $0.05(.22)$ & -1.46 \\
\hline History of Violent Offenses & $0.07(.26)$ & $0.09(.28)$ & $0.07(.26)$ & -1.17 \\
\hline History of Property Offenses & $0.13(.34)$ & $0.15(.36)$ & $0.14(.34)$ & -1.12 \\
\hline History of Public Safety Offenses & $0.08(.27)$ & $0.12(.33)$ & $0.09(.28)$ & $-2.62 *$ \\
\hline
\end{tabular}

$* \mathrm{p}<.05, * * \mathrm{p}<.01, * * * \mathrm{p}<.001$ 
Table 2

Descriptive Statistics by Housing Mobility $(\mathrm{N}=1,936)$

\begin{tabular}{|c|c|c|c|c|c|c|c|c|c|}
\hline \multirow[t]{2}{*}{ Variable } & \multicolumn{2}{|c|}{$\begin{array}{l}\text { 1. Zero Moves } \\
(\mathrm{N}=547)\end{array}$} & \multicolumn{2}{|c|}{$\begin{array}{l}\text { 2. 1-2 Moves } \\
(\mathrm{N}=807)\end{array}$} & \multicolumn{2}{|c|}{$\begin{array}{c}\text { 3. 3-4 Moves } \\
(\mathrm{N}=370)\end{array}$} & \multicolumn{2}{|c|}{$\begin{array}{l}\text { 4. 5+ Moves } \\
(\mathrm{N}=212)\end{array}$} & \multirow[t]{2}{*}{ Significant Differences* } \\
\hline & M & SD & M & SD & M & SD & M & SD & \\
\hline \multicolumn{10}{|l|}{ Parole Characteristics } \\
\hline Restriction Parole & 0.19 & 0.39 & 0.20 & 0.40 & 0.27 & 0.44 & 0.24 & 0.43 & $1<3$ \\
\hline Parole Length (days) & 773.93 & 317.14 & 822.33 & 338.60 & 918.68 & 404.90 & 1000.46 & 414.90 & $1<3 ; 1<4 ; 2<3 ; 2<4 ; 3<4$ \\
\hline Non-Residential Placement & 0.09 & 0.28 & 0.18 & 0.39 & 0.24 & 0.43 & 0.26 & 0.44 & $1<2 ; 1<3 ; 1<4$ \\
\hline Length of Incarceration (months) & 82.95 & 55.76 & 76.86 & 54.56 & 68.85 & 53.65 & 59.15 & 49.54 & $1>3 ; 1>4 ; 2>4$ \\
\hline \multicolumn{10}{|l|}{ Offender Demographics } \\
\hline Age at Parole & 39.30 & 12.10 & 37.70 & 11.28 & 34.02 & 10.25 & 31.98 & 9.17 & $1>3 ; 1>4 ; 2>3 ; 2>4$ \\
\hline Non-white & 0.27 & 0.45 & 0.29 & 0.46 & 0.38 & 0.49 & 0.40 & 0.49 & $1<3 ; 1<4 ; 2<3 ; 2<4$ \\
\hline Ever Married & 0.50 & 0.50 & 0.49 & 0.50 & 0.40 & 0.49 & 0.35 & 0.48 & $1>3 ; 1>4 ; 2>3 ; 2>4$ \\
\hline Less than High School & 0.55 & 0.50 & 0.62 & 0.49 & 0.68 & 0.47 & 0.73 & 0.44 & $1<2 ; 1<3 ; 1<4 ; 2<4$ \\
\hline High School Diploma & 0.32 & 0.47 & 0.29 & 0.46 & 0.26 & 0.44 & 0.25 & 0.43 & \\
\hline More than High School Diploma & 0.13 & 0.34 & 0.09 & 0.28 & 0.05 & 0.23 & 0.02 & 0.14 & $1>2 ; 1>3 ; 1>4 ; 2>4$ \\
\hline Low Assault Risk & 0.02 & 0.13 & 0.02 & 0.16 & 0.04 & 0.19 & 0.08 & 0.27 & $1<4 ; 2<4$ \\
\hline Medium Assault Risk & 0.74 & 0.44 & 0.76 & 0.43 & 0.76 & 0.43 & 0.76 & 0.43 & \\
\hline High Assault Risk & 0.24 & 0.42 & 0.22 & 0.41 & 0.17 & 0.40 & 0.17 & 0.37 & \\
\hline Low Property Risk & 0.72 & 0.45 & 0.65 & 0.48 & 0.61 & 0.49 & 0.56 & 0.50 & $1>3 ; 1>4 ; 2>4$ \\
\hline Medium Property Risk & 0.17 & 0.38 & 0.20 & 0.40 & 0.25 & 0.43 & 0.27 & 0.44 & $1<3 ; 1<4$ \\
\hline High Property Risk & 0.11 & 0.31 & 0.15 & 0.35 & 0.15 & 0.35 & 0.17 & 0.38 & \\
\hline Child Molester & 0.21 & 0.41 & 0.26 & 0.44 & 0.16 & 0.37 & 0.26 & 0.44 & $2>3 ; 3<4$ \\
\hline \multicolumn{10}{|l|}{ Criminal History } \\
\hline Only Sex Offenses in History & 0.77 & 0.42 & 0.76 & 0.43 & 0.69 & 0.47 & 0.66 & 0.48 & $1>3 ; 1>4 ; 2>4$ \\
\hline History of Drug Offenses & 0.03 & 0.17 & 0.05 & 0.22 & 0.07 & 0.26 & 0.07 & 0.26 & $1>3$ \\
\hline History of Violent Offenses & 0.07 & 0.26 & 0.07 & 0.26 & 0.10 & 0.30 & 0.06 & 0.23 & \\
\hline History of Property Offenses & 0.12 & 0.32 & 0.13 & 0.34 & 0.15 & 0.36 & 0.18 & 0.38 & \\
\hline History of Public Safety Offenses & 0.07 & 0.26 & 0.08 & 0.27 & 0.09 & 0.29 & 0.16 & 0.37 & $1<4 ; 2<4 ; 3>4$ \\
\hline
\end{tabular}

$* \mathrm{p}<.05$, Bonferroni Test 
Table 3. Multinomial Logistic Regression $(N=1,936)$

\begin{tabular}{|c|c|c|c|c|c|c|}
\hline \multirow[b]{2}{*}{ Variable } & \multicolumn{2}{|c|}{1 to 2 Moves vs. Zero Moves } & \multicolumn{2}{|c|}{3 to 4 Moves vs. Zero Moves } & \multicolumn{2}{|c|}{ 5+ Moves vs. Zero Moves } \\
\hline & $B(S E)$ & $\operatorname{Exp}(B)$ & $B(S E)$ & $\operatorname{Exp}(B)$ & $B(S E)$ & $\operatorname{Exp}(B)$ \\
\hline Intercept & $0.41(.20)$ & & $-0.56(.25)$ & & $-1.28(.31)$ & \\
\hline \multicolumn{7}{|l|}{ Parole Characteristics } \\
\hline Restriction Parole & $0.13(.15)$ & 1.14 & $0.68(.18)$ & $1.98 * * *$ & $0.62(.23)$ & $1.87 * *$ \\
\hline Parole Length & $0.15(.08)$ & 1.17 & $0.46(.09)$ & $1.59 * * *$ & $0.59(.11)$ & $1.81 * * *$ \\
\hline Non-residential Placement & $0.86(.18)$ & $2.36 * * *$ & $1.25(.20)$ & $3.48 * * *$ & $1.34(.23)$ & $3.81 * * *$ \\
\hline Incarceration length (months) & $-0.00(.00)$ & 1.00 & $-0.00(.00)$ & 1.00 & $-0.01(.00)$ & $0.99 * *$ \\
\hline \multicolumn{7}{|l|}{ Offender Demographics } \\
\hline Age at parole (std.) & $-0.12(.07)$ & 0.89 & $-0.43(.10)$ & $0.65 * * *$ & $-0.59(.14)$ & $0.55 * * *$ \\
\hline Non-white & $0.07(.13)$ & 1.07 & $0.37(.16)$ & $1.44^{*}$ & $0.61(.19)$ & $1.85 * * *$ \\
\hline Ever married & $0.17(.14)$ & 1.19 & $0.26(.17)$ & 1.29 & $0.21(.21)$ & 1.24 \\
\hline High school diploma & $-0.21(.13)$ & 0.81 & $-0.29(.16)$ & 0.75 & $-0.30(.20)$ & 0.74 \\
\hline More than high school & $-0.50(.19)$ & $0.61 * *$ & $-0.86(.28)$ & $0.42 * * *$ & $-1.86(.54)$ & $0.16 * * *$ \\
\hline Low assault risk & $0.32(.41)$ & 1.37 & $0.69(.46)$ & 2.00 & $1.51(.47)$ & $4.51 * * *$ \\
\hline High assault risk & $-0.13(.16)$ & 0.88 & $-0.22(.20)$ & 0.80 & $-0.37(.25)$ & 0.69 \\
\hline Low property risk & $-0.17(.15)$ & 0.85 & $-0.32(.18)$ & 0.72 & $-0.48(.22)$ & $0.62 *$ \\
\hline High property risk & $0.20(.22)$ & 1.22 & $-0.16(.26)$ & 0.86 & $0.05(.30)$ & 1.05 \\
\hline Child Molester & $0.27(.14)$ & 1.30 & $-0.18(.19)$ & 0.84 & $0.60(.21)$ & $1.83 * *$ \\
\hline \multicolumn{7}{|l|}{ Criminal History } \\
\hline History of Drug Offenses & $0.45(.32)$ & 1.57 & $0.47(.35)$ & 1.59 & $0.17(.41)$ & 1.19 \\
\hline History of Violent Offenses & $0.04(.24)$ & 1.04 & $0.43(.27)$ & 1.54 & $-0.26(.39)$ & 0.77 \\
\hline History of Property Offenses & $0.06(.18)$ & 1.06 & $0.20(.22)$ & 1.22 & $0.33(.26)$ & 1.39 \\
\hline History of Pub. Safety Offenses & $0.05(.23)$ & 1.05 & $-0.01(.27)$ & 0.99 & $0.73(.29)$ & $2.08 *$ \\
\hline-2 Log Likelihood & & & $4,608.00$ & & & \\
\hline Model $\chi^{2}$ & & & $348.35 * * *$ & & & \\
\hline df & & & 54 & & & \\
\hline Cox and Snell $\mathrm{R}^{2}$ & & & .17 & & & \\
\hline
\end{tabular}

